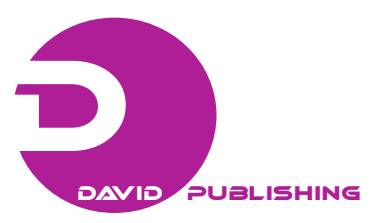

\title{
Advanced Methods of Evaluating Benefits from Improved Flood Immunity in Queensland
}

\author{
Wayne Davies \\ Department of Transport and Main Roads, Queensland 4000, Australia
}

\begin{abstract}
The regular occurrence and the high costs of flooding to both road agencies and communities is a strong impetus to investigate the methodologies applied to evaluating flood immunity road projects. Very little literature exists on methods of evaluating the benefits of improving flood immunity through better road infrastructure. This paper attempts to address some of the numerous issues hindering the accurate evaluation of flood immunity road projects. The methodologies presented in this paper are designed to evaluate benefits that are not normally included or not fully considered in evaluations; such benefits include reduced flood related road accidents, costs of not travelling during the closure period and additional costs from unanticipated flood events. A key focus of the paper is the consideration of the evaluation of improved flood immunity from a network perspective rather than the typical approach of evaluating flood immunity projects in isolation to each other. The application of the proposed methodologies is demonstrated with a hypothetical example of a typical rural network subjected to regular flooding. The results of the analysis, conducted using the proposed methodologies, reveals that the currently applied methodologies account for less than half the likely value of benefits of a package of projects that will prevent the complete isolation of communities during serious flood events.
\end{abstract}

Key words: Flood immunity, economic evaluation, cost benefit analysis, road closures.

\section{Introduction}

Roads in rural Queensland are frequently subject to flooding. The accurate prediction of the occurrence of these floods is not always possible as Queensland frequently experiences unpredictable weather. Flooding can potentially cause millions of dollars of damage to road infrastructure [1] as well as millions of dollars worth of damage to the economy and society [2]. The severe flooding in early 2010 cost TMR (transport and main roads) over \$110 million in damages across all regions [3]. Prior to floods in late 2010 and early 2011 more than 15\% of Queensland State projects were NDRRA (natural disaster relief and recovery arrangements) and most of these projects involve treating roads damaged by flooding [4]. Preliminary estimates of the total costs to road infrastructure of the late 2010 and early 2011 floods are expected to be close to $\$ 4.5$ billion [5]. TMR [6]

Corresponding author: Wayne Davies, master, research fields: transport economics, cost benefit analysis and road project evaluation. E-mail: wmd03@yahoo.com. have identified 36 sites along the Bruce Highway ${ }^{1}$ between Brisbane and Cairns that flood during major flooding events. Four of those sites resulted in road closures of over five days in the recent 2011 floods.

The areas most impacted by floods are the South West, Central West, Far North and Northern Regions of Queensland. Table 1 contains the rivers that have flooded most frequently and the number of times they have flooded between 2000 and 2010.

The flooding of the Tully, Haughton, Herbert, Murray and Burdekin rivers can cause road closures along the Bruce Highway in the Northern Region, while the flooding of the Mary River can cause road closures along the Bruce Highway near Gympie (Population: 42,820 [7]) and Maryborough (Population: 21,501 [8]) possibly significantly reducing access to highly populated areas. The

\footnotetext{
${ }^{1}$ The Bruce Highway is a major highway linking Brisbane to northern Queensland; the Bruce Highway has a length of over $1,600 \mathrm{~km}[9]$.
} 
flooding of the Warrego River can cause reduced access to Charleville (Population: 3,728 [10] from the north. The flooding of the Thomson, Barcoo, Diamantina and Georgina rivers as well as the Eyre and Cooper creeks can cause road closures along the Barkly and Landsborough highways, which form an important freight route between Mount Isa (North West Region) and Longreach (Central West Region). The flooding of the Paroo and Bullo rivers can cause road closures of the developmental roads connecting the small towns of Quilpie, Thargomindah, Eromanga and Eulo.

The projected NDRRA costs on state controlled and national highways from 2010 to 2014 according to $\mathrm{TMR}^{2}$ [4] are given in Table 2.

Queensland's northern regions are expected to experience the highest flood related road infrastructure costs. Most of these costs can be accredited to the severe flooding in these areas in recent years, improving flood immunity will greatly reduce these costs in the future.

Flood immunity projects are difficult to evaluate, very little literature exists pertaining to the methods of evaluating these projects. This paper proposes some feasible methods of assessing the benefits and costs associated with improved flood immunity. To demonstrate how these methods can be applied, an example of a bridge upgrade has been included in this paper. The methods suggested in this paper can help decision makers prioritize flood immunity projects by identifying which road closures are more costly.

\section{Issues}

The evaluation of a flood immunity project involves the consideration of many factors. These factors can vary in complexity depending on the location of the project site and extent of the network.

\footnotetext{
${ }^{2}$ These values are current as of November 17, 2010 according to RIP Live databases, these figures may vary from those published in the QTRIP (Queensland Transport and Roads Investment Program).
}

The collection and organization of data often poses the largest and trickiest part of evaluating a flood immunity project. The analyst is confronted with a number of issues, one such issue is the determining of which data is relevant. This issue can not be easily addressed as the data required depends on the detail and the methodology applied to the evaluation. Sources of data are not always available, thus, forcing the analyst to either simplify the evaluation or make assumptions. This section of the paper indentifies relevant issues relating to networks, key evaluation parameters, interrelated projects, flood related accident costs and wider economic benefits.

\subsection{Networks}

The network plays an essential role in the evaluation of flood immunity projects. Good knowledge of the network enables a more accurate prediction of the benefits obtained from an improvement in flood immunity. Important aspects of the network that should be considered are the size of the network, the existence of alternative routes, the types of vehicles that can access these routes and the types of vehicles utilizing the network.

When encountered with a flood, the road user normally has three options, divert, wait or not travel [11]. The decision of which option to take depends on which option the road user deems to cost $^{3}$ the least. If floods can be anticipated, the road user is more likely to select an optimal strategy during the flood, thus making the prediction of road user behavior easier to make. If the flood is unanticipated, road user behavior is less likely to be optimal and road user costs will be higher during a flood [12].

In the case of an anticipated flood, the analyst should obtain the optimal road user response to flooding [13]. The factors, which influence this response,

\footnotetext{
${ }^{3}$ Costs in this case refer to the road user's perceived costs,
} which includes travel time costs. 
Table 1 Flooding frequency of rivers in Queensland.

\begin{tabular}{lllllllllllllll}
\hline Ranking River & Region & 2000 & 2001 & 2002 & 2003 & 2004 & 2005 & 2006 & 2007 & 2008 & 2009 & 2010 & Total \\
\hline 1 & Paroo & South West & 6 & 0 & 2 & 1 & 1 & 1 & 0 & 5 & 3 & 4 & 4 & 27 \\
2 & Bulloo & South West & 7 & 1 & 2 & 0 & 1 & 1 & 0 & 4 & 3 & 2 & 4 & 25 \\
3 & Cooper Creek & Central West & 5 & 1 & 1 & 1 & 2 & 0 & 1 & 3 & 3 & 3 & 4 & 24 \\
4 & Tully & Far North & 3 & 2 & 0 & 1 & 3 & 1 & 2 & 3 & 2 & 4 & 0 & 21 \\
5 & Georgina & Central West & 4 & 1 & 0 & 0 & 3 & 2 & 0 & 2 & 1 & 4 & 2 & 19 \\
6 & Diamantina & Central West & 4 & 1 & 0 & 0 & 2 & 0 & 0 & 3 & 1 & 5 & 3 & 19 \\
7 & Thomson & Central West & 5 & 2 & 1 & 0 & 1 & 0 & 0 & 1 & 2 & 3 & 4 & 19 \\
8 & Barcoo & Central West & 5 & 2 & 1 & 0 & 1 & 0 & 0 & 1 & 2 & 1 & 3 & 16 \\
9 & Haughton & Northern & 3 & 0 & 1 & 0 & 0 & 1 & 1 & 1 & 3 & 2 & 3 & 15 \\
10 & Condamine & South West & 2 & 0 & 0 & 2 & 1 & 0 & 0 & 0 & 4 & 0 & 5 & 14 \\
11 & Eyre Creek & Central West & 3 & 0 & 0 & 0 & 2 & 2 & 0 & 2 & 0 & 3 & 1 & 13 \\
12 & Don River & Whitsunday & 2 & 0 & 1 & 0 & 0 & 1 & 1 & 2 & 3 & 1 & 2 & 13 \\
13 & Herbert & Northern & 2 & 1 & 1 & 0 & 1 & 0 & 1 & 2 & 1 & 2 & 1 & 12 \\
14 & Warrego & South West & 2 & 0 & 1 & 1 & 1 & 0 & 0 & 1 & 1 & 0 & 5 & 12 \\
15 & Murray & Northern & 0 & 0 & 0 & 0 & 3 & 0 & 2 & 2 & 1 & 3 & 0 & 11 \\
21 & Burdekin & Northern & 1 & 1 & 1 & 0 & 0 & 1 & 0 & 1 & 0 & 1 & 2 & 8 \\
23 & Mary & Wide Bay & 0 & 1 & 0 & 0 & 1 & 0 & 0 & 1 & 1 & 1 & 2 & 7 \\
\hline
\end{tabular}

Source: Adapted from Bureau of Meteorology [14].

Table 2 Projected NDRRA costs for the next five years prior to the 2011 floods.

\begin{tabular}{|c|c|c|c|c|}
\hline NDRRA & \multicolumn{2}{|c|}{ OSCR (other stated controlled roads) } & \multicolumn{2}{|c|}{ National } \\
\hline Regions & Cost (\$) & No. Projects & Cost (\$) & No. Projects \\
\hline Darling Downs & $6,159,000$ & 43 & 476,000 & 6 \\
\hline Metropolitan & $1,129,000$ & 30 & 111,000 & 3 \\
\hline Fitzroy & $14,540,000$ & 33 & 450,000 & 2 \\
\hline Northern & $88,886,000$ & 4 & $33,159,000$ & 7 \\
\hline Far North & $278,684,000$ & 174 & $45,703,000$ & 15 \\
\hline North West & $55,697,000$ & 27 & $33,682,000$ & 16 \\
\hline South West & $20,501,000$ & 15 & - & 0 \\
\hline Central West & $29,233,000$ & 41 & $2,340,000$ & 9 \\
\hline Mackay/Whitsunday & $27,495,000$ & 138 & $17,747,000$ & 19 \\
\hline Wide Bay/Burnett & 481,000 & 12 & 25,000 & 2 \\
\hline North Coast & $2,039,000$ & 56 & 111,000 & 3 \\
\hline South Coast & $5,231,000$ & 13 & 550,000 & 1 \\
\hline Total & $530,075,000$ & 586 & $134,354,000$ & 83 \\
\hline Average cost per project & 904,565 & & $1,618,723$ & \\
\hline
\end{tabular}

Source: TMR [15] RIP Live accessed November 17, 2010.

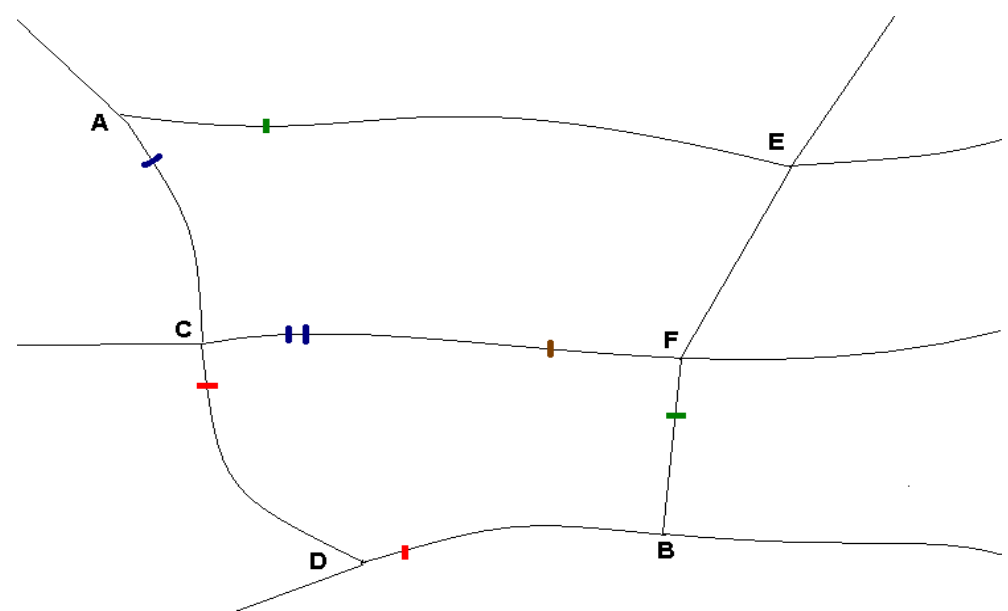

Fig. 1 Simple mud map of a road network. Legend: Red lines-Q2 Bridges/Culverts; Brown lines-Q10 Bridges (mass limit 20 tonnes); Blue lines-Q20 Bridges; Green lines-Q50 Bridges. 
are the road user's value of time, the flexibility of travel options ${ }^{4}$, the duration of the road closure, the length of the diversion route if a diversion route exists, the type of vehicle the road user is driving and any other factors particular to the road or network. Data may or may not be available for all these factors and in these cases, the analyst may wish to exclude the factor or make some assumptions to its value.

In the case of an unanticipated flood, the analyst could still proceed in determining the optimal road user response but consider this response as a best-case scenario. Additional factors need to be considered such as the impact of imperfect information about durations of road closures and the most appropriate diversion routes considering other roads may have also been impacted by the flood. In the case of unanticipated flooding, sensitivity analysis around possible road user behavior could improve the robustness of the evaluation.

Some routes will attract road users with a higher value of time. These routes are likely to have a high percentage of commercial vehicles. Depending on the type of business located in the region, commercial vehicle road users could value time very differently depending on the urgency of the journey. If the flood can be anticipated, the road users with a high value of time can either travel before or after the floods arrive. If the flood is unanticipated, the timing of journeys can not be easily changed. Considering this logic, the road user costs of unanticipated flooding are likely to be higher than the costs of anticipated flooding.

The length of the diversion route plays a significant role in determining the behavior of the road user. Long diversion routes that add to the cost of the journey are unattractive and may cause more road users to wait or not travel. In some cases, diversion routes do not exist at all, forcing road users to wait or not travel. Some networks allow for multiple

\footnotetext{
${ }^{4}$ Flexibility of travel options refers to the road user's flexibility in travelling at different times or to different locations.
}

diversion routes, which change depending on the extent of the flooding and mass limits of the roads. Fig. 1 is a mud map of a simple rural network with multiple possible diversion routes.

Route ACDB is the fastest route between Towns A and $\mathrm{B}$ but unfortunately approximately every two years the sections $\mathrm{CD}$ and $\mathrm{DB}$ are closed because of flooding. The route ACFB is the next fastest route but a bridge along section CF has a mass limit of 20 tonnes. Therefore, heavy vehicles will divert using the route AEFB, which is considerably longer than ACDB. The route ACFB may also be flooded on occasions as section CF is closed $1 / 5$ the time $C D$ and $D B$ are closed. Route AEFB will rarely flood, thus, providing road users with a reliable route from $A$ to $B$.

Anticipated floods will not create a great disturbance to this network as viable diversion routes exist for road users who wish to travel or if trips are more flexible, road users can reschedule trips to periods before or after the flooding. Unanticipated floods could cause a greater disturbance to this network. Some road users may need to backtrack to Town B if the bridge along DB is impassable. Road users may not know if route ACFB or AEFB should be taken if information is not available to whether the bridge along CF is passable, thus, causing further delays. Town $\mathrm{D}$ could be isolated from the rest of the network without important resources. The costs to isolated towns or communities are not fully recognized in TMR cost benefit analysis methodology.

\subsection{Key Parameters and Their Impact on Project Benefits in Currently Practiced TMR Cost Benefit Analysis}

Many flood immunity projects do not have enough quantifiable benefits when analyzed with currently practiced cost benefits analysis approaches. The four key determinants of quantifiable benefits for flood immunity projects are AADT (annual average daily traffic), AATOC (annual average time of closure), ADC (average duration of closure) and the length of 
the diverting route.

AADT is a key determinant of benefits in all road project evaluations. A road with an AADT of 10,000 vehicles will have fifty times more benefits than a road with 200 vehicles assuming ceteris paribus. Flooding is predominantly an issue in rural areas where AADT is normally low. The benefits per vehicle maybe large but if the AADT is low, the overall benefits will not cover the costs of building a bridge or culvert to reduce road closures.

The AATOC is a parameter unique to projects involving road closures. The number of hours a road is closed has a large impact on the total benefits of the project. The benefits normally captured in a cost benefits analysis are the immediate benefits of reduced road closure times. These benefits come in the form of reduced waiting time, reduced VOC (vehicle operating costs) and reduced TTC (travel time cost). Costs of not travelling during a road closure and the long-term growth of communities are excluded from analysis. A standard AATOC is normally applied to all vehicle types. In reality, road closure times can vary depending on the vehicle type. A road may have a load limitation for a period of time (“dry-back" period) after the road has been reopened to cars [11]. This load restriction imposes a cost on heavy vehicle road users that is often not considered.

The ADC is another parameter unique to projects involving road closures. The ADC can have a large impact on the overall benefits of a project as the ADC influences road user behavior. If road closures are long, a higher percentage of road users will either divert or not travel. If the road closures are short, more road users will wait for the roads to re-open. This behavior will vary depending on the extent of information available regarding the duration of the road closures. If flooding is anticipated, the durations of the road closures are likely to be known and road users will act more efficiently. If the flooding is unanticipated, road users may choose less efficient options.

The costs per road user during an anticipated road closure are likely to decrease as road user's shift from not travelling to diverting as diversion routes become more viable and then as the duration shortens road users will switch from diverting to waiting.

Shown in Fig. 2 is an example of a possible cost structure to a road user depending on when the road user encounters a road closure. Initially, the road user would not travel, as the cost of diverting is higher than the value of the journey to the road user. After duration of $x$, an alternative diversion route becomes available, the cost of taking this diversion route is less than the cost of not making the journey ${ }^{5}$. The road user will choose to travel along the diversion route until the cost of waiting and the cost of the journey along the original route is less than the cost of travelling along the diversion route. The red line in Fig. 2 illustrates the road user's optimal behavior, as the road becomes closer to re-opening.

In the case of an unanticipated flood, the duration of closure is uncertain and alternative routes are uncertain, too. The parameters in Fig. 2 can therefore be roughly estimated, and are likely to be inaccurate. This inaccuracy will cause road users to make inefficient choices, thus resulting in higher costs per a road closure. Currently practiced cost benefit analysis will not accurately detect these inefficiencies.

Another key determinant of overall benefits for a flood immunity project is the length of the diversion route. Long diversion routes could greatly increase the costs of road closures, if the ADC is long. A further complicating issue is that diversion routes could change depending on the extent of flooding. If the flood is small and localized, the diversion route could be short as other roads are not flooded. If the flood is large and covers a large area, the diversion route could become longer or no longer exist if the entire local network is flooded. Determining the diversion routes

\footnotetext{
${ }^{5}$ The cost of not making the journey is the difference between the value of the journey to the road user and the cost of the journey to the road user when the road is not closed.
} 


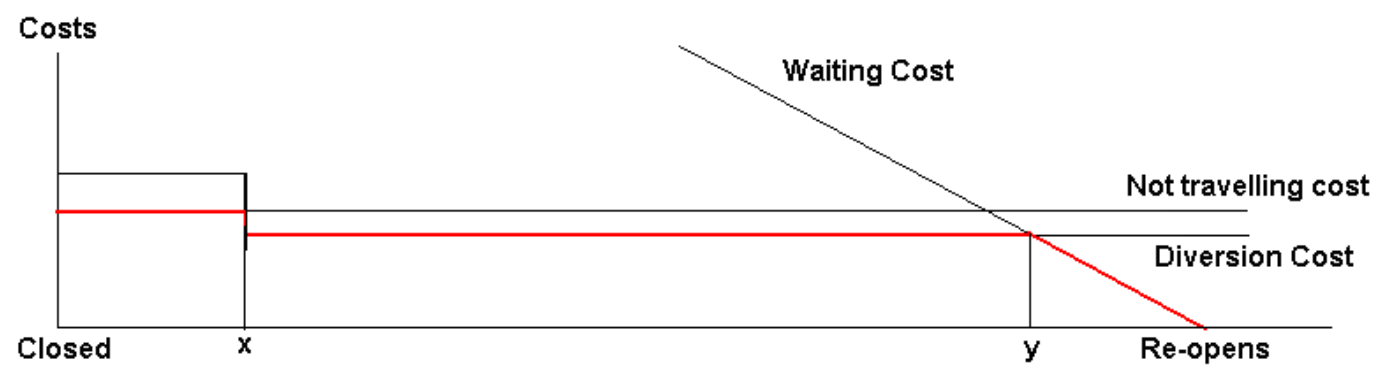

Fig. 2 Possible road user behavior during a road closure.

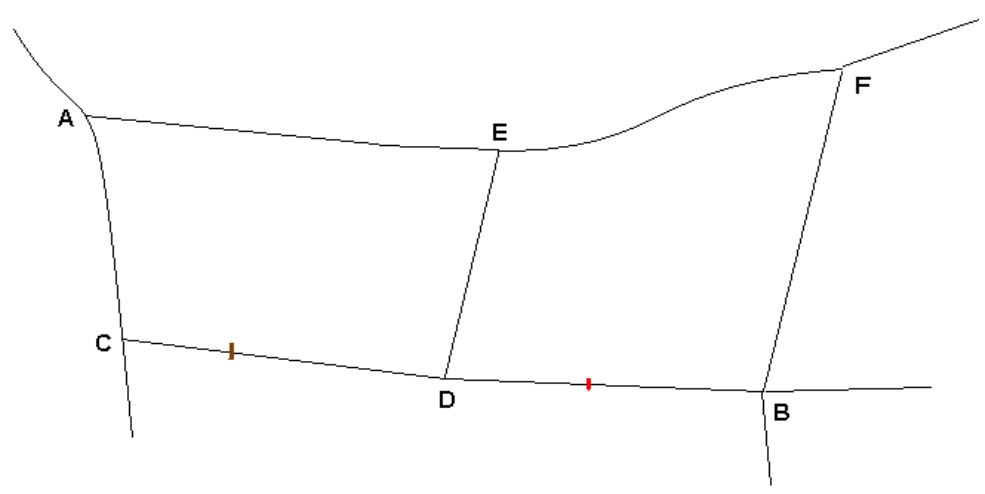

Fig. 3 Mud map of an example of project dependency.

to use in the evaluation can be complicated and often the shorter diversion routes are selected, thus the additional costs of diverting during larger floods are negated $^{6}$.

\subsection{Interrelated Projects}

If one part of a network is inundated, it is likely that other parts of the network are also inundated. It is possible that other flood immunity projects will be proposed to resolve flooding in other parts of the network. When a project is first suggested, the diversion route may be large but this diversion route could be significantly reduced when another route is upgraded.

Another important aspect that should be considered is the flood immunity along the entire route. Improving the flood immunity on one part of the route may only improve the flood immunity of the entire route to a certain extent. Other sections of the route could still be prone to occasional flooding. This other

\footnotetext{
${ }^{6}$ This conclusion was derived from reading a sample of BCA
} reports conducted in recent years. section of the route may be upgraded later. The uncertainty surrounding this could make evaluating the current flood immunity project difficult, thus invoking the use of even more assumptions. The optimal choice of diversion route may or may not be changed by the upgrade of the other part of the route.

If the author assumes the same legend applied to Fig. 1 is applied to Fig. 3, the diversion route in the base case is AEFB for road users travelling between Town A and B. It can be seen that on average CD is flooded every 10 years. This is inconsequential in the base case for vehicles travelling between Town A and $\mathrm{B}$, as whenever $\mathrm{CD}$ is flooded $\mathrm{DB}$ is also flooded. In the project case, if the bridge along $\mathrm{DB}$ is upgraded to a Q50 bridge ${ }^{7}$, the flooding along $\mathrm{CD}$ becomes relevant, as $\mathrm{ACDB}$, the shortest route, is not always viable, therefore, the route AEDB is taken instead.

\subsection{Flood Related Accidents}

From 1788 to 1996, at least 2,213 people have died

\footnotetext{
${ }^{7} \mathrm{~A}$ Q50 bridge is built to a standard where it will only flood during a Queensland 50-year or worse flood event.
} 
as a result of over 926 recorded floods [16]. According to Ashley and Ashley [17], 63\% of flood fatalities occur in vehicles. Jonkman and Keiman [18], identified that $33 \%$ of all flood related activities involved drowning in vehicles, most of these occurred because road users attempted to cross flooded roads. If the authors apply these rates to the fatalities that occur in Australia, approximately an average of 1.5 people die in their vehicles and approximately an average of 0.75 people die crossing flooded roads per flood. Improving flood immunity would decrease the occurrence of these fatalities.

\subsection{Wider Economic Benefits}

Flooding reduces road access and therefore will likely reduce the economic growth of regions isolated by floods. Improved flood immunity may generate traffic that will directly benefit from improved access. This generated traffic will likely produce wider economic benefits to the community. Department for Transport [19] has conducted extensive research into wider economic benefits in general. Wider economic benefits of improved flood immunity could be substantial and should be considered for further research.

\section{Approach}

To overcome some of the issues discussed in the previous section, this paper offers some approaches and methodologies. The extent of these approaches can be applied depend on the network and the necessity of a detailed analysis. This section also explains how these same methodologies can be applied to determine which roads are more feasible for flood immunity upgrades.

A simple mud map of the network can be used to ascertain the extent of the network to be analysed. The mud map only needs to contain the network of roads that are likely to be flooded and the diversion routes that road users are likely to use during a flood. Figs. 1 and 3 are examples of such mud maps. All sections of the mud map, which are prone to flooding, should be identified. Data should be collected on the extent of the flooding and types of flood immunity treatment that these sections have received or are proposed to receive.

With the use of relevant data and mud maps, diversion routes can be determined based on the extent of the flooding. Road and traffic parameters need to be established for the diversion routes. Once all the available information is gathered, an informed decision to the exact approach can be made. Complete information will enable a detailed analysis, while incomplete information may require assumptions to be made or the analysis could be simplified to cater to the information available.

\subsection{The Model}

A flooding model has been constructed to estimate the costs of flooding to road agencies and road users. This model expands upon the current methodology applied to flood immunity projects. This model attempts to address most of the deficiencies in the current model. This model is intended to work in synchronisation with current CBA models by applying the values per VKT (vehicle kilometre travelled) derived from these models. The issues addressed in the flooding model are those of network impacts, unanticipated flooding, underestimated flooding benefits, accounting for different diversion routes by different vehicle types, flood related accidents and assessing the impact of interrelated projects.

The road agency costs applied to this model are the costs to the road agency to restore the road to an acceptable standard. These costs are averaged and allocated annually. Road user costs are the standard costs for road closures (diverting, not travelling and waiting costs). These costs are calculated across the network for each route for various severity of flooding. Severity of flooding has been categorized as minor, moderate and major according to the Bureau of Meteorology cited by Attorneys-General's 
Department [20]. Each category has been divided into anticipated and unanticipated flooding.

The model requires TTC and VOC outputs per VKT per route from conventional cost benefit analysis models. Considering the potential number of routes impacted by flooding, the model does not endogenously calculate TTC and VOC, these values can be entered directly into the flooding model. The length of the original route and the diversion route are required to determine the additional costs of diverting. The ADC is used to determine the costs of waiting for the road to re-open during a road closure. In the case of an unanticipated flood, road users are assumed to have imperfect information about the duration of closure. To account for the imperfect information, an upper and lower bound of the expected duration of road closure have been incorporated into the model. The maximum cost of a road user is willing to pay to make a journey ${ }^{8}$ is used in the model to estimate the elasticity of demand the road users have for travel along the route. The additional costs of diverting, the duration of closure and maximum cost of a road user is willing to pay to make a journey are used to determine the road user behavior during a flood.

\subsection{Calculation of Road User Behavior and Flooding Costs}

Fig. 2 presented a relationship between the duration of the road closure and road user behavior. The flooding model is used to calculate the optimal road user behavior given perfect (anticipated flood) and imperfect (unanticipated flood) information. Road user behavior given perfect information can be assumed to be optimal. Road users will select the option that minimizes their perceived costs. To derive this behavior, perceived costs of diverting, waiting and not travelling need to be estimated. Costs of diverting are TTC, VOC, accident and externality. TTC are normally accepted as perceived [21], VOC

\footnotetext{
${ }^{8}$ This is the value of the destination to the road user, this value can vary quite considerably depending on the nature of the journey.
}

are accepted by some as perceived and not by others, accidents and externalities are not normally considered perceived. For the purpose of this model, TTC and VOC are assumed to be perceived. TTC and VOC per vehicle are calculated by Eqs. (1) and (2), respectively:

$$
\begin{gathered}
T T C_{\text {Div }}=\left(\left(T T C_{k m(D R)} \times \operatorname{AdjF}_{(D R)} \times \operatorname{Dist}_{(D R)}\right)-\right. \\
\left.\left.\left(T T C_{k m(O R)} \times \operatorname{AdjF}_{(O R)} \times \operatorname{Dist}_{(O R)}\right)\right)\right)^{9} \\
V O C_{\text {Div }}=\left(\left(T_{k m(D R)} \times \operatorname{Dist}_{(D R)}\right)-\right. \\
\left.\left(T T C_{k m(O R)} \times \operatorname{Dist}_{(O R)}\right)\right)
\end{gathered}
$$

$T T C_{D i v}=$ Additional TTC per vehicle for diverting; $T T C_{k m(D R)}=$ TTC per $\mathrm{km}$ of the diversion route;

$T T C_{k m(O R)}=$ TTC per $\mathrm{km}$ of the original route;

$\operatorname{Adj} F_{(D R)}=$ TTC adjustment factor of the diversion route;

$\operatorname{AdjF}_{(O R)}=$ TTC adjustment factor of the original route;

$\operatorname{Dist}_{(D R)}=$ Section length ${ }^{10}(\mathrm{~km})$ of the diversion route;

$\operatorname{Dist}_{(O R)}=$ Section length $(\mathrm{km})$ of the original route;

$V O C_{\text {Div }}=$ Additional VOC per vehicle for diverting.

TTC is multiplied by an additional factor to account for a potential difference in the value of travel time for different types of floods. This parameter should have a higher value for floods that are unanticipated. The perceived costs of diverting is the sum of the additional TTC per vehicle and the additional VOC per vehicle $\left(P \operatorname{cost}_{D i v}=T T C_{D i v}+V O C_{D i v}\right)$. The perceived costs of diverting are used to determine when the option of waiting becomes more favourable than diverting. The point in time when waiting is more favourable to diverting has been denoted as the "equilibrium waiting time", waiting before the equilibrium is reached is considered not feasible if the authors assume road users select the least cost option.

\footnotetext{
${ }^{9}$ Costs of using the diversion route are assumed to exceed the costs of using the original route, as the original route is the preferred route during a non-flood event.

${ }^{10}$ The length of road is between the start and finish of the defined diversion route and original route.
} 
The equilibrium waiting time is given in Eq. (3):

$$
W T_{E}=\min \left(\frac{\text { Post }}{\text { Div }}_{\text {Cost }_{\text {perhr }}}, \frac{\text { MaxCostNT }}{\text { Cost }_{\text {perhr }}}, D C\right)
$$

where,

$W T_{E}=$ Equilibrium waiting time (hours);

PCost $_{\text {Div }}=$ Perceived costs of diverting;

Cost $_{\text {per hr }}=$ Cost of one hour of waiting;

MaxCostNT = Maximum perceived cost of not travelling;

$D C=$ Duration of closure.

The equilibrium waiting cost is assumed to equal the perceived cost of diverting or if a diversion does not exist, the equilibrium waiting time is the minimum cost of not travelling or the duration of the road closure.

The maximum cost of not travelling ${ }^{11}$ has been used to determine a linear demand function for travel. The maximum cost of not travelling is the maximum value of the journey to the road user minus the cost of travelling along the original route. The percentage of road users not travelling when waiting is not feasible or when a diversion route does not exist, $N T$ is given in Eq. (4):

$$
N T=\min \left(\frac{\text { PCost }_{\text {Div }}}{\text { MaxCostNT }}, \frac{D C \times \text { Cost }_{\text {perhr }}}{\text { MaxCostNT }}, 1\right)^{12}
$$

The percentage of road users diverting when waiting is not feasible (D) or the percentage of road users waiting when a diversion route does not exist (W) equals to one minus (NT). The formulae for NT and D are expressed graphically in Fig. 4.

The percentage of road users opting to not travel when waiting is not feasible is $\mathrm{XY} / 0 \mathrm{Y}$ and the percentage of road users opting to divert when waiting is not feasible is $0 \mathrm{X} / 0 \mathrm{Y}$.

The costs of diverting are calculated as the sum of perceived costs, accident costs and externalities, the formula is given in Eq. (5):

\footnotetext{
${ }^{11}$ Maximum cost of not travelling can be adjusted according to the duration of the road closure depending on whether the opportunity cost of the alternative activity is sensitive to time. ${ }^{12}$ This equation holds true, as the demand function is assumed linear.
}

$$
\begin{gathered}
T D C=\left(\text { PCost }_{D i v}+\text { Accident }_{\text {Div }}+\text { Externality }_{\text {Div }}\right) \times \\
\frac{\left(D T-W T_{E}\right) \times A A D T \times D}{24}
\end{gathered}
$$

Accident costs are derived based on crash costs per model road state defined in the Transport and Main Roads cost benefit analysis model, which are derived from Austroads paper AP-R184 [22]. Externality costs are calculated based on vehicle kilometres travelled with 2007 unit values provided by Austroads paper IR-156/08, which are updated using the CPI (consumer price index) provide by the ABS (Australian Bureau of Statistics) [23].

The average costs of waiting per road closure are half the perceived costs of diverting if the author assumes the traffic volume is evenly distributed across the duration of the road closure. For road users who either not travel or wait when diverting is not feasible, the costs of waiting are calculated as an eighth the perceived costs of diverting. An eighth is derived by halving the costs of not travelling and the costs of waiting when diverting is not feasible, which is half the costs of waiting when diverting is feasible, which is half of the perceived costs of diverting. The costs of waiting are given in Eq. (6):

$$
\begin{aligned}
W C= & 1 / 2 \times \text { PCost }_{\text {Div }} \times \frac{W T_{E} \times A A D T \times(1-N T)}{24}+ \\
& 1 / 8 \times P \operatorname{Cost}_{\text {Div }} \times \frac{W T_{E} \times A A D T \times N T}{24} 13
\end{aligned}
$$

The costs of not travelling are derived from the perceived costs of diverting and the percentage of vehicles not travelling, the formula is given in Eq. (7):

$$
\begin{array}{r}
N T C=1 / 2 \times \text { PCost }_{\text {Div }} \times \frac{\left(D c-W T_{E}\right) \times A A D T \times N T}{24}+ \\
1 / 8 \times \text { PCost }_{\text {Div }} \times \frac{W T_{E} \times A A D T \times N T}{24}
\end{array}
$$

The average costs of not travelling per road closure are half the perceived costs of diverting if the authors assume the demand for travel to locations that require the use of the closed route is linear. For road users who either not travel or wait when diverting is not feasible, the costs of not travelling are calculated as an

\footnotetext{
${ }^{13}$ If a diversion route does not exist, PCost ${ }_{\text {Div }}$ should be replaced with $\operatorname{Min}\left(\operatorname{Max} \operatorname{CostNT}, D C \times \operatorname{Cost}_{\text {perhr }}\right)$, this same assumption is applied to Eq. (6).
} 


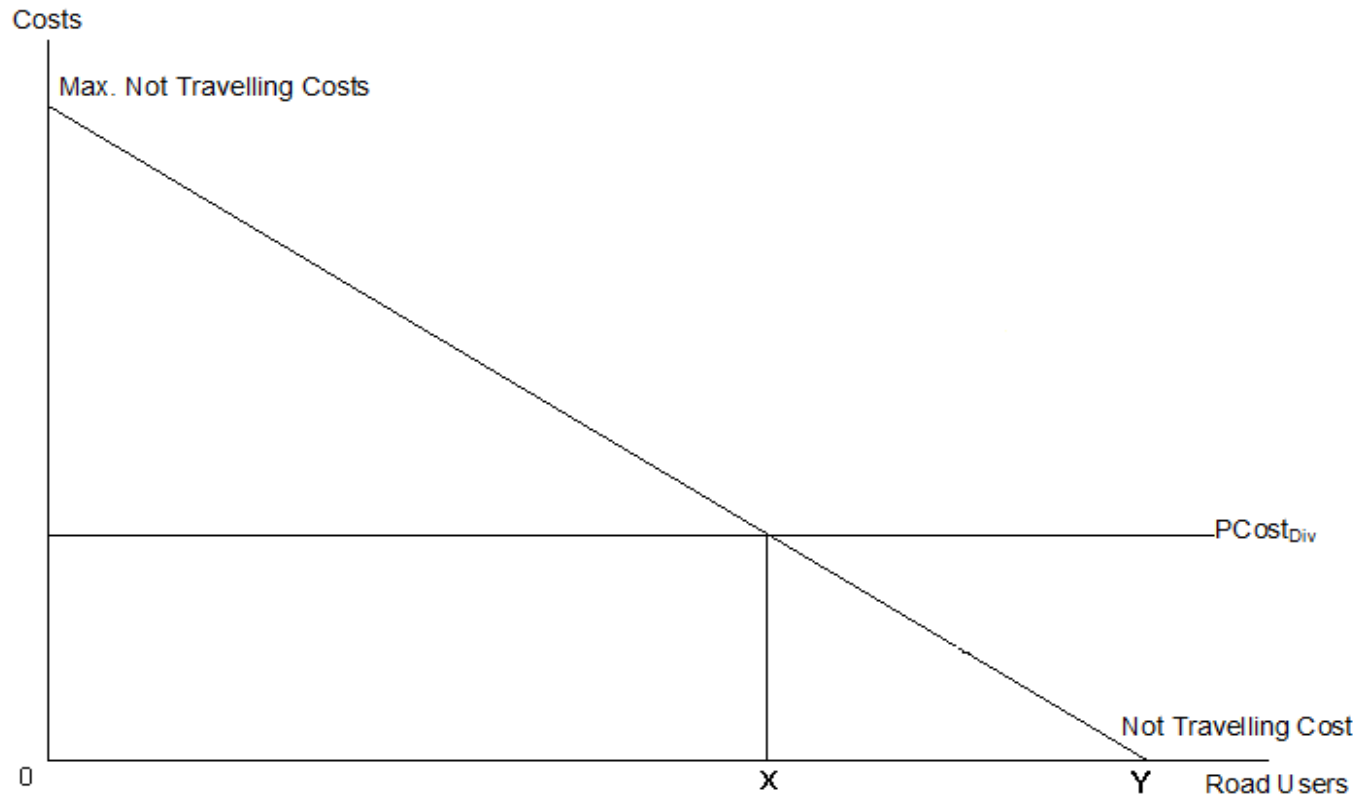

Fig. 4 Linear demand function used to determine number of road users not travelling.

eighth of the perceived costs of diverting ${ }^{14}$. In Appendix A, the formulae are expressed and explained in three-dimensional graphs. The road closure costs are calculated annually by multiplying the diverting, waiting and not travelling costs by the AEP (annual exceedance probability) ${ }^{15}$.

Costs of repairing roads damaged by floods (NDRRA) are allocated to the relevant sections of roads damaged by flooding. Both a base case and a project case estimate should be established. These costs should be lower in the project case than the base case and should be considered as maintenance benefits of improved flood immunity. Flood related accident costs have been calculated for major floods by multiplying the average number of flood related fatalities described in Section 2.4 by the Austroads unit cost per fatality [24] ${ }^{16}$. The removal of mass restrictions on upgraded roads could provide additional benefits during the flood period as well as

\footnotetext{
${ }^{14}$ The cost of waiting and the costs of not travelling are assumed equal for the period when diverting is not feasible.

${ }^{15} \mathrm{AEP}$ is the probability that flooding will occur, this probability is calculated with the formula $A E P=1-\exp \left(\frac{-1}{A R I}\right)$, ARI is the average recurrence interval of flooding [25]. ${ }^{16}$ Formula applied to the model is given Appendix A.
}

improved access all year round. The benefits of the removal of mass limits during the flood period can be assessed in the flood model but benefits for the rest of year should be calculated independently to this model.

\subsection{An Example of the Application of Methodologies} Discussed

To demonstrate the capturing of benefits using the currently practiced cost benefit analysis approach and the approach suggested in this paper, two hypothetical bridge projects have been assessed. They have been assessed using CBA6, partial endogenous road user behavior CBA model and the proposed flood immunity model.

CBA6 is the Transport and Main Roads CBA tool, the partial endogenous road user behavior (PERUB) CBA model is an excel based spreadsheet derived from the NIMPAC algorithms harmonized in Austroads paper AP-R264/05 [26] with partially endogenously derived road user behavior during road closures.

The approaches suggested in this paper have not been applied to an actual evaluation, therefore, a hypothetical case study of a plausible scenario has 
been derived. The flood immunity projects evaluated in this case study are two bridge upgrades in an area of low AADT with limited access during severe floods.

The collection of data of the types of floods that the region experiences are important as the nature of the floods could greatly influence the results of the evaluation. In the instance of this case study, data of the types of floods are assumed available. The full set of data applied to the evaluation is given in Appendix B.

In this example, TTC and VOC costs per vehicle have been extracted from TMR cost benefit analysis software (CBA6). The weighted average costs per vehicle for each section have been entered into the model using the formula given in Eq. (8):

$$
W A C=\sum_{i=1}^{i=n}\left(\frac{\text { CostPerVeh icle } \times \text { No.Vehicles }}{(1+r)^{i}}\right) / \sum_{i=1}^{i=n}\left(\frac{\text { No.Vehicles }}{(1+r)^{i}}\right)
$$

where,

$i=$ Year of evaluation;

$r=$ Discount rate.

This average is applied to the model and extrapolated over the life of the project based on projected growth rates and discount rates. Data is not always available for all the relevant factors, hence, assumptions should be made. To obtain a more accurate result, the number of assumptions should be kept to a minimum.

\subsection{Results of Models}

The results obtained from CBA6 and PERUB are quite similar. Both models consider an original route and a diversion route between $\mathrm{C}$ and $\mathrm{B}$. In this model, all vehicles are able to divert to avoid the road closures. The mud map applied to these models is given in Fig. 5. The proposed model is applied to a larger part of the network as shown in Fig. 6.

Final and intermediate destinations of vehicles are required as inputs to this model. CBA6 and PERUB only require the AADT of each section of road. The results of the three models are presented in Table 3 and input data is provided in Appendix B.

The benefits derived from the proposed model are considerably higher than both those obtained from CBA6 and PERUB. The main source of this difference is that the costs of not travelling are not fully identified by the other two models.

Town D loses access to all five other neighboring towns when any form of flooding occurs. The impacts of lack of access to Town D are ignored by CBA6 and PERUB, which are focused on road users travelling

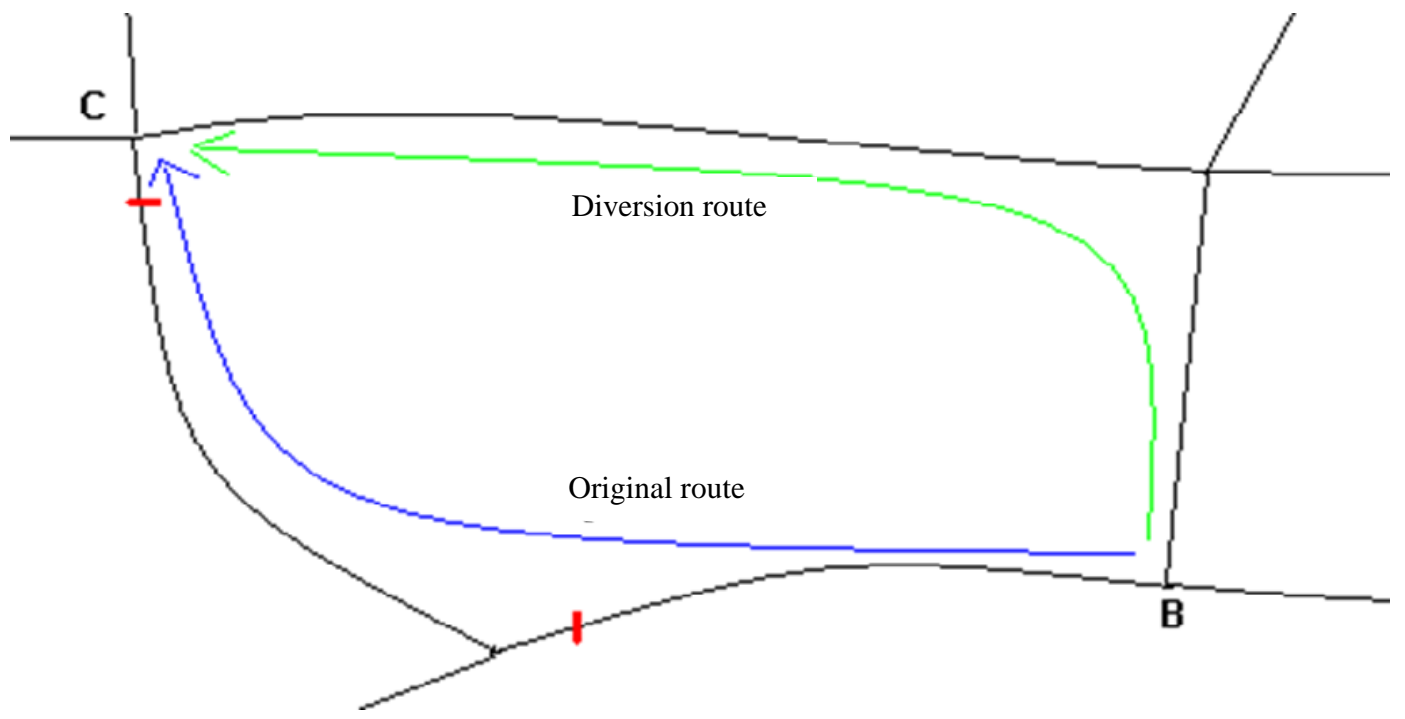

Fig. 5 Mud map of network considered in CBA6 and PERUB methodologies. 


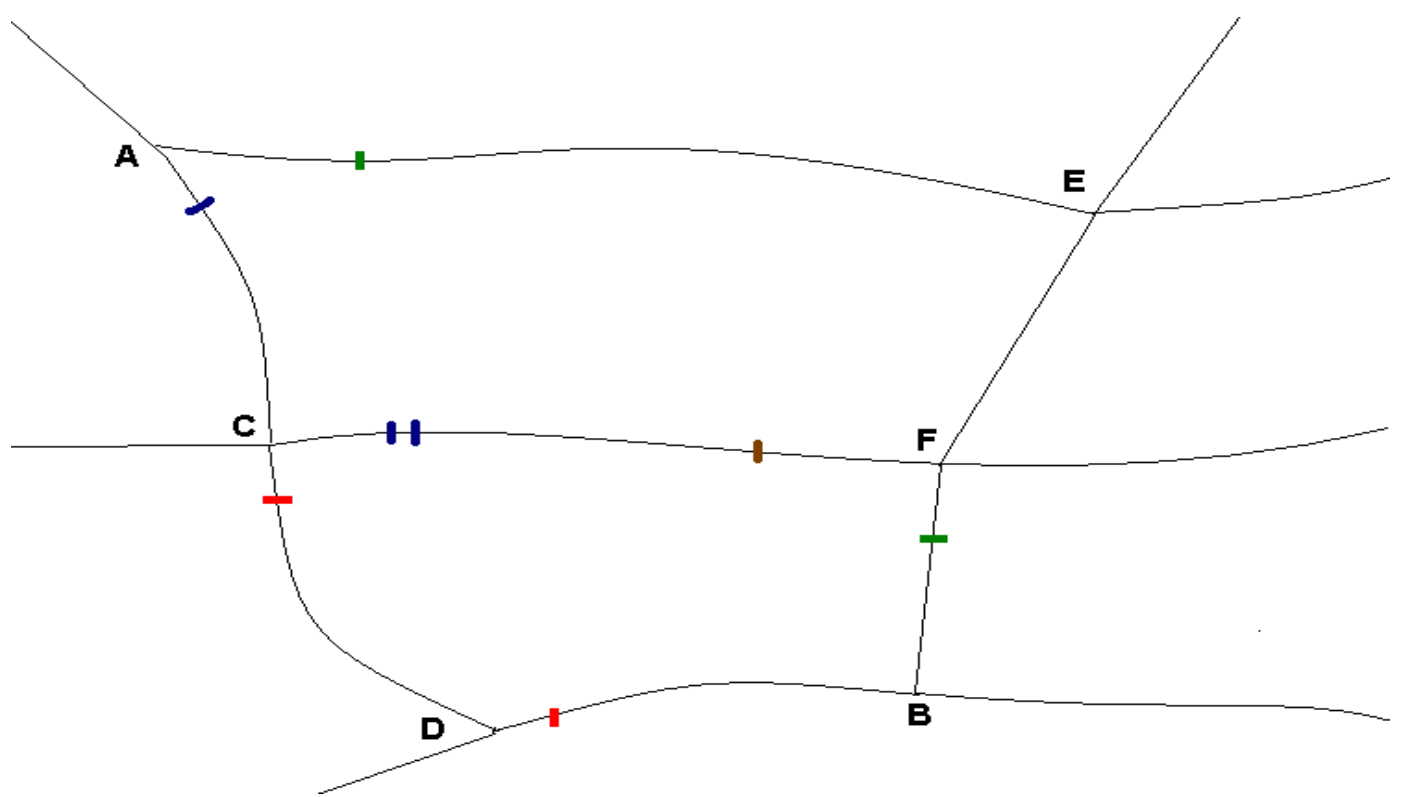

Fig. 6 Mud map applied to the example. Legend: Red lines-Q2 Bridges/Culverts; Brown lines-Q10 Bridges (mass limit 20 ton); Blue lines-Q20 Bridges; Green lines-Q50 Bridges.

Table 3 Results generated by models.

\begin{tabular}{llll}
\hline Results & PERUB & CBA6 & Proposed \\
\hline Total costs & $\$ 3,692,585$ & $\$ 3,692,585$ & $\$ 3,692,585$ \\
Capital & $\$ 5,769,231$ & $\$ 5,769,231$ & $\$ 5,769,231$ \\
Maintenance costs & $-\$ 1,454,079$ & $-\$ 1,454,079$ & $-\$ 1,454,079$ \\
Residual value & $-\$ 622,567$ & $-\$ 622,567$ & $-\$ 622,567$ \\
Total benefits & $\$ 343,423$ & $\$ 760,222$ & $\$ 6,250,695$ \\
VOC savings & $\$ 134,870$ & $\$ 51,991$ & $\$ 103,138$ \\
TTC savings & $\$ 128,570$ & $\$ 59,967$ & $\$ 53,197$ \\
Accident cost savings & $-\$ 15,477$ & $-\$ 2,145$ & $\$ 17,976$ \\
Flood related accident cost savings & $\mathrm{NA}$ & $\mathrm{NA}$ & $\mathbf{N}$ \\
Emission cost savings & $\$ 7,902$ & $\mathrm{NA}$ & $\mathrm{NA}$ \\
Environment cost savings & $\$ 4,845$ & $\mathrm{NA}$ & $\mathrm{NA}$ \\
Secondary cost savings & $\$ 251$ & $\mathrm{NA}$ & $\mathrm{NA}$ \\
Other cost savings & $\$ 80,191$ & $\$ 650,409$ & $\$ 33,035$ \\
Waiting time cost savings (diversion) & $\$ 71$ & $\mathrm{NA}$ & $\$ 565,772$ \\
Not travelling cost savings (diversion) & $\$ 2,201$ & & $\$ 5,112,322$ \\
\hline Indicators & & $-\$ 2,932,363$ & \\
\hline NPV (net present value) & $-\$ 3,349,162$ & $-\$ 4,386,442$ & $\$ 2,558,110$ \\
NPV (excluding NDRRA savings) & $-\$ 4,803,241$ & 0.49 & $\$ 1,104,030$ \\
NBIR (net benefit investment ratio) & 0.42 & 0.21 & 1.44 \\
BCR (benefit cost ratio) & 0.09 & 0.15 & 1.69 \\
BCR (excluding NDRRA savings) & 0.07 & & 1.21 \\
\hline
\end{tabular}

the entire route between $\mathrm{CB}$. CDB also acts as a heavy vehicle diversion route for heavy vehicle road users travelling between CF during periods of no flooding. When CDB is flooded, CAEF is the only viable diversion route for the heavy vehicles; this route is an additional $55 \mathrm{~km}$. If the two bridges along CDB are sufficiently upgraded, CDB can act as a diversion route for road users utilizing other parts of the network, which are only affected during major floods. During minor and moderate floods, five trips are no longer possible forcing road users not to travel. During a major flood, nine trips are no longer possible. 
After the two bridges are upgraded, all trips become available to all vehicle types as $\mathrm{CDB}$ becomes a possible diversion route for other flood-affected areas.

The projected reduced NDRRA costs, which can be included in either of the above three models, adds an additional $\$ 1.45$ million worth of benefits to the projects. This value substantially improves the NPV of all three models. In this example, a clear discernable value of projected NDRRA costs has been allocated to the project site. In reality, collection and allocation of such costs can be difficult, and estimates of these costs need to be made using historical data from the region.

The proposed flooding model can be used to assess the impact of upgrading different combinations of bridges to achieve the optimal bridge upgrade program for particular areas. Upgrading of the bridges along section $\mathrm{CD}$ and $\mathrm{DB}$ have been evaluated separately and compared with the option of upgrading both bridges. Table 4 shows for the comparisons.

Upgrading of only one bridge greatly improves access during minor and moderate floods but does not provide many benefits during major floods, this is especially the case for the upgrading of the bridge along section CD. During heavy floods, Towns $\mathrm{C}$ and $\mathrm{D}$ become isolated from the other towns. If the bridge along Section DB is the only bridge upgraded, Town C becomes completely isolated from the network. Both bridges need to be upgraded for complete access to the regional network. The NPV of upgrading both bridges is greater than the sum of NPVs from both the $\mathrm{CD}$ and DB bridge upgrades. Upgrading of only one bridge also produces negative TTC, VOC, accident and externality benefits, these negative benefits occur because the upgrading of only one bridge provides improved access to towns $\mathrm{C}$ and $\mathrm{D}$ through long diversion routes rather than the original routes.

The proposed model has a number of limitations, and the largest of these is the availability of data to feed into the model. Currently, traffic volumes are available per section of road but not per route. This data can be made available through transport studies but these studies are often costly to conduct. The

Table 4 Options analysis.

\begin{tabular}{llll}
\hline Results & Both bridges & DB bridge & CD bridge \\
\hline Total costs & $\$ 3,692,585$ & $\$ 1,846,292$ & $\$ 1,846,292$ \\
Capital & $\$ 5,769,231$ & $\$ 2,884,615$ & $\$ 2,884,615$ \\
Maintenance costs & $-\$ 1,454,079$ & $-\$ 727,040$ & $-\$ 727,040$ \\
Residual value & $-\$ 622,567$ & $-\$ 311,283$ & $-\$ 311,283$ \\
Total benefits & $\$ 6,250,695$ & $\$ 2,800,296$ & $\$ 2,746,188$ \\
VOC savings & $\$ 103,138$ & $-\$ 188,936$ & $-\$ 90,690$ \\
TTC savings & $\$ 53,197$ & $-\$ 99,765$ & $-\$ 59,385$ \\
Accident cost savings & $\$ 17,976$ & $-\$ 84,712$ & $-\$ 37,841$ \\
Flood related accident cost savings & $\$ 365,255$ & $\$ 182,628$ & $\$ 182,628$ \\
Externality cost savings & $\$ 33,035$ & $-\$ 68,092$ & $-\$ 25,659$ \\
Waiting time cost savings(diversion) & $\$ 565,772$ & $\$ 304,284$ & $\$ 289,259$ \\
Not travelling cost savings (diversion) & $\$ 5,112,322$ & $\$ 2,754,889$ & $\$ 2,487,877$ \\
\hline Indicators & & & $\$ 899,895$ \\
\hline NPV & $\$ 2,558,110$ & $\$ 954,003$ & 1.31 \\
NBIR & 1.44 & 1.33 & 1.49 \\
BCR & 1.69 & 1.52 & $\$ 1,424,025$ \\
\hline Benefits according to flood type & & & $\$ 652,502$ \\
\hline Minor floods & $\$ 1,780,819$ & $\$ 669,661$ \\
Moderate floods & $\$ 1,235,212$ & $\$ 1,269,691$ & $\$ 2,746,188$ \\
Major floods & $\$ 3,234,664$ & $\$ 621,674$ & $\$ 2,800,296$ \\
Total & $\$ 6,250,695$ & & \\
\hline
\end{tabular}


quantity of data required for the proposed model is quite substantial compared to current models such as CBA6. The collection of this data could be time consuming and the results of the analysis will take longer to obtain. The proposed model does not generate values for travel time or vehicle operating costs per $\mathrm{km}$ of travel, these values need to be calculated prior to using the proposed model.

\section{Conclusions}

The costs to the road network and the costs to society from flooding can be enormous. The solution of improving flood immunity can greatly reduce these costs if the right projects are introduced at the right places. The current practiced methodology does not sufficiently account for the possible benefits obtainable from a large number of flood immunity projects. The model proposed in this paper addresses some of the issues surrounding the evaluation of benefits of flood immunity projects. These issues include identifying the impact of a project on the immediate network, identifying the impact of flood severity, valuing flood related accident costs, incorporating NDRRA flooding costs, valuing unanticipated flood costs, valuing costs of not travelling and the determination of endogenous road user behavior. As seen from the results presented in Section 3.4, addressing the issues mentioned greatly increases the quantifiable benefits of flood immunity projects that relieve isolation to communities during flood events. Incorporating generated traffic and wider economic benefits would further enhance the assessment of benefits of some flood immunity projects and would be an appropriate next step forward from this paper.

\section{References}

[1] Earth Science Australia, Flood Damage Assessment Case Study-Johnstone River Flooding, Earth Science Australia, http://earthsci.org/flood/j_flood04/flood/ (accessed Apr. 21, 2010).

[2] Geoscience Australia, Flood Information, Australian
Government, 2010, http://www.ga.gov.au/hazards/flood/ (accessed Apr. 21, 2010).

[3] TMR Infrastructure Program Performance Report, Department of Transport and Main Roads, Queensland Government, 2010.

[4] Roads Implementation Program Development 2009-10 to 2013-14, Department of Transport and Main Roads, Queensland Government, 2010.

[5] ABC Far North Queensland, Flood Threat Eases on Qld's Tablelands, 2011, http://www.abc.net.au/news/stories (accessed Apr. 4, 2011).

[6] Flooding Locations, Flood Closures and Flood Immunity Standards for the Bruce Highway (Brisbane to Cairns) (Presentation), Department of Transport and Main Roads, Queensland Government, 2011.

[7] National Regional Profile: Gympie (R) (Local Government Area), Australian Bureau of Statistics, 2010, http://www.abs.gov.au/AUSSTATS/ (accessed Apr. 4, 2011).

[8] Maryborough (Urban Centre/Locality), 2006 Census QuickStats, Australian Bureau of Statistics, 2007, http://www.censusdata.abs.gov.au (accessed Apr. 4, 2011).

[9] Bruce Highway, http://en.wikipedia.org/wiki/ Bruce_Highway (accessed Mar. 4, 2011).

[10] Charleville (Urban Centre/Locality), 2006 Census QuickStats, Australian Bureau of Statistics, 2007, http://www.censusdata.abs.gov.au (accessed Apr. 4, 2011).

[11] Flooding on Roads in Queensland, Department of Transport and Main Roads, Queensland Government, 2010.

[12] N. Cernaianu, Risk management in road transport, munich personal RePEc archive, Technical Paper, University of Bucharest, Romania, 2010.

[13] Cost Benefit Analysis Manual, Department of Transport and Main Roads, Queensland Government, Brisbane, 2011.

[14] Queensland Flood Summary 2000 onwards, Bureau of Meteorology, Australian Government, 2011, http://www.bom.gov.au/hydro/flood/qld/fld_history/flood sum_2000 (accessed Mar. 30, 2011).

[15] Roads Implementation Program Development 2009-10 to 2013-14 Live, Department of Transport and Main Roads, Queensland Government, 2010.

[16] L. Coates, Flood fatalities in Australia, 1788-1996, Aust. Geogr. 30 (1999) 391-408.

[17] S.T. Ashley, W.S. Ashley, Flood fatalities in the United States, Journal of Applied Meteorology and Climatology 47 (2008) 805-818.

[18] N.J. Jonkman, I. Kelman, An Analysis of the Causes and Circumstances of Flood Disaster Deaths, Blackwell 
Publishing, UK, 2005, pp. 75-97.

[19] Transport, Wider Economic Benefits and Impacts on GDP, Department for Transport, 2006, London.

[20] Australian Emergency Management Terms Thesaurus, Attorney-General's Department, Australian Government, 2009, http://library.ema.gov.au (accessed May 30, 2010).

[21] National Guidelines for Transport Systems Management in Australia, 4 Appraisal of initiatives, Commonwealth of Australia, Australian Transport Council, Canberra, 2006.

[22] Economic Evaluation of Road Investment Proposals: Improved Predictions Model for Road Crash Savings,
Austroads, AP-R184, 2001.

[23] 6401.0-Consumer Price Index, Australian Bureau of Statistics, Australia, June 2010.

[24] Austroads Internal Report: Update of RUC Unit Values to June 2007, Austroads, IR-156/08, Austroads, 2008.

[25] ARI and AEP, Bureau of Meteorology, Australian Government, 2010, http://www.bom.gov.au/hydro/has/ ari_aep.shtml (accessed Apr. 21, 2010).

[26] Economic Evaluation of Road Investment Proposals: Harmonisation of Non-Urban Road User Cost Models, Austroads, AP-R264/05, 2005.

\section{Appendix A: Mathematical and diagrammatical derivation of flooding costs.}

Mathematical derivations of formulae using Figs. A1-A4:

Formula: TDC (total diverting costs)

$$
T D C=\left(\text { PCost }_{\text {Div }}+\text { Accident }_{\text {Div }}+\text { Externality }_{\text {Div }}\right) \times \frac{\left(D C-W T_{E}\right) \times A A D T \times D}{24}
$$

Calculated using Fig. A2:

$$
T D C=(B C+A B) \times C D \times D E
$$

where,

$B C=$ Perceived costs;

$A B=$ Accident and externality costs;

$C D=$ Duration of closure-equilibrium waiting time;

$D E=$ Number of road users diverting per hour.

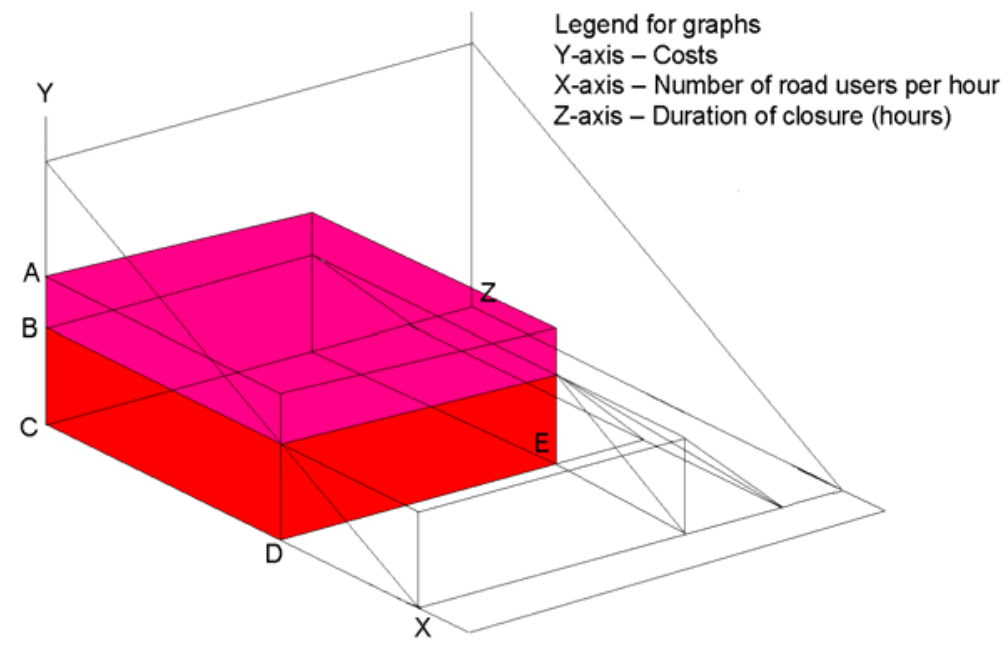

Fig. A1 Diversion costs. 


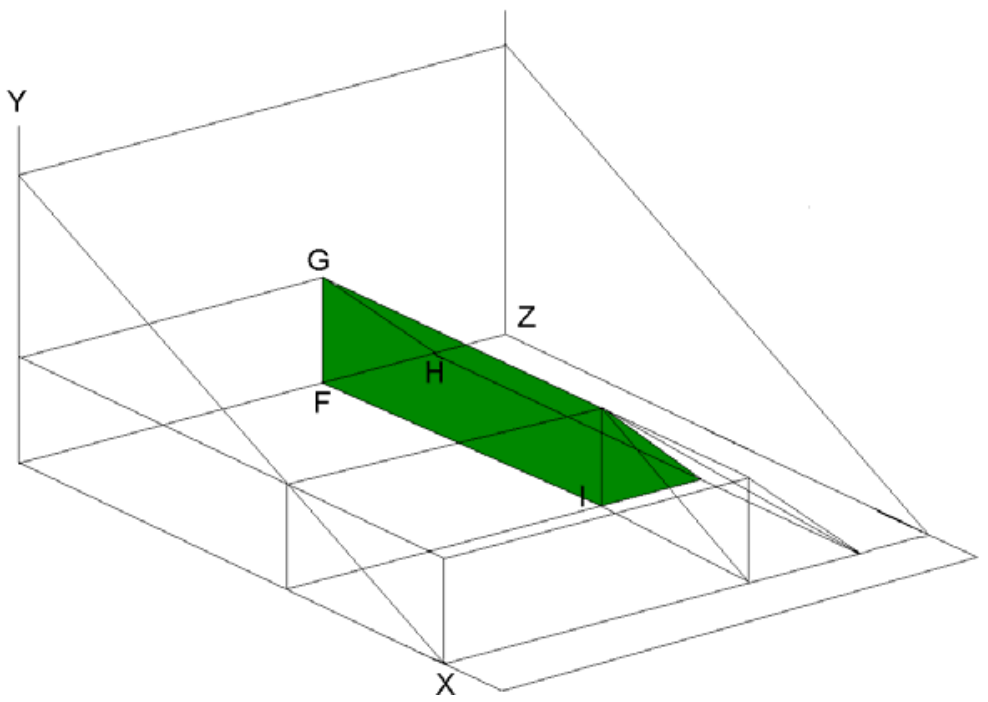

Fig. A2 Waiting costs for road users who choose to travel.

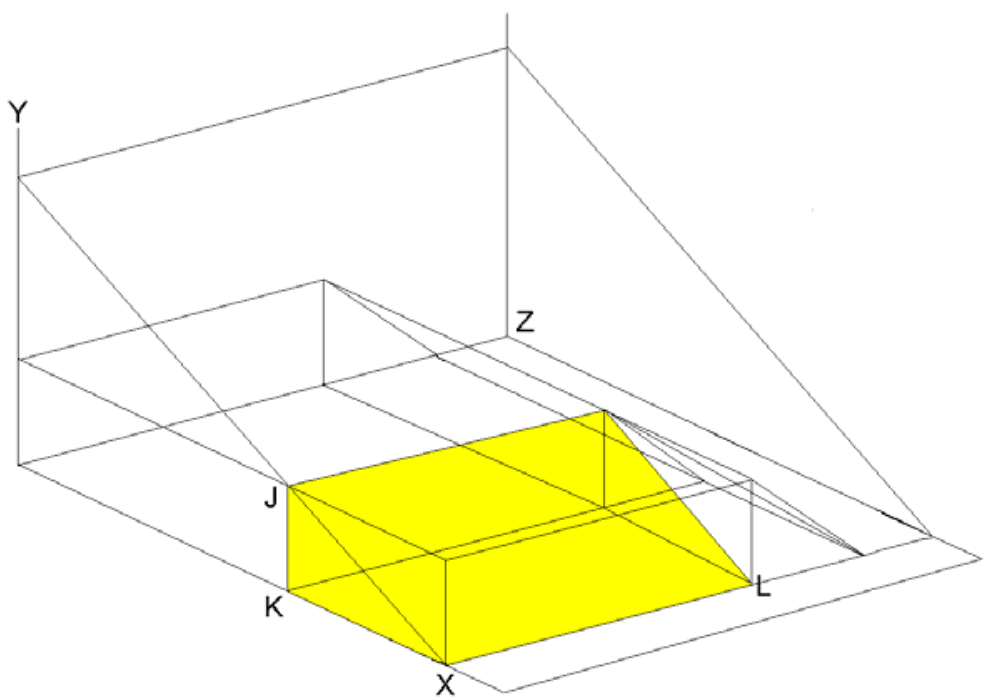

Fig. A3 Not travelling costs when waiting is not a feasible option.

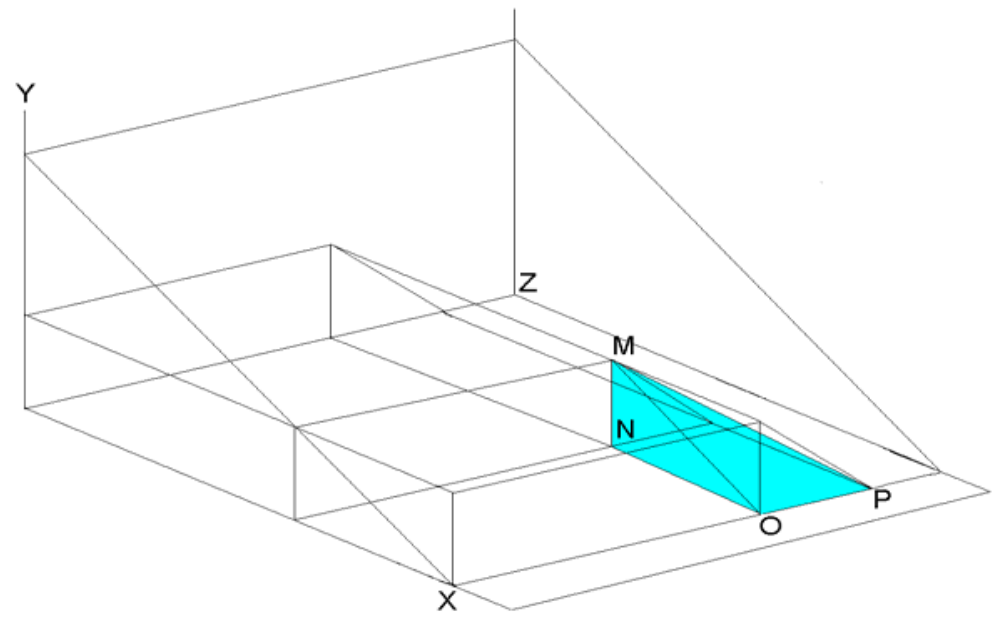

Fig. A4 Waiting and not travelling costs when diverting is not a feasible option. 
Formula: total waiting costs:

$$
W C=1 / 2 \times P \operatorname{Cost}_{\text {Div }} \times \frac{W T_{E} \times A A D T \times(1-N T)}{24}+1 / 8 \times P \operatorname{Cost}_{\text {Div }} \times \frac{W T_{E} \times A A D T \times N T}{24}
$$

Calculated using Figs. A2 and A4:

$$
W C=(1 / 2 \times G F \times F H \times F I)+1 / 2 \times(1 / 4 \times M N \times N O \times O P)
$$

where,

$G F=$ Perceived costs;

$F H=$ Equilibrium waiting time;

$F I=$ Number of road users diverting per hour;

$M N=$ Perceived costs;

$N O=$ Equilibrium waiting time;

$O P=$ Number of road users not travelling per hour.

Formula: total NTC (not travelling costs):

$$
N T C=1 / 2 \times P \operatorname{Cost}_{\text {Div }} \times \frac{\left(D c-W T_{E}\right) \times A A D T \times N T}{24}+1 / 8 \times P \operatorname{Cost}_{b_{i v}} \times \frac{W T_{E} \times A A D T \times N T}{24}
$$

Calculated using Figs. A3 and A4:

$$
N T C=(1 / 2 \times J K \times X L \times K X)+1 / 2 \times(1 / 4 \times M N \times N O \times O P)
$$

where,

$J K=$ Perceived costs;

$X L=$ Duration of closure - equilibrium waiting time;

$K X=$ Number of road users not travelling per hour;

$M N=$ Perceived costs;

$N O=$ Equilibrium waiting time;

$O P=$ Number of road users not travelling per hour.

Formula: FRAC (flood related accident costs):

$$
\text { FRAC }=\frac{\text { Flooded Sections Considered }}{\text { Total Area Flooded }} \times \text { AEP } \times \text { AccRate } \times \text { Cost per Fatality }
$$

\section{Appendix B: Evaluation input data.}

Table B1 Input data according to section.

\begin{tabular}{lcccccccc}
\hline Sections & Pte cars & Com cars & Non-artic & Articulated & B-doubles & Pte cars & Length & MRS $^{18}$ \\
\hline AC & 100 & 77 & 9 & 5 & 4 & 5 & 32 & 10 \\
CD & 105 & 79 & 8 & 7 & 10 & 6 & 40 & 10 \\
DB & 121 & 91 & 15 & 7 & 9 & 4 & 38 & 10 \\
AE & 84 & 65 & 7 & 4 & 6 & 2 & 92 & 8 \\
EF & 184 & 148 & 22 & 9 & 3 & 2 & 34 & 12 \\
FB & 171 & 140 & 20 & 5 & 4 & 2 & 25 & 12 \\
CF & 65 & 49 & 8 & 8 & 0 & 0 & 62 & 10 \\
\hline
\end{tabular}

\footnotetext{
${ }^{17}$ Non-articulated vehicles

${ }^{18}$ MRS (Model Road State)
} 
Table B2 Input data according to route.

\begin{tabular}{lrrrrrrrr}
\hline Routes & AADT & Pte cars & Com cars & Non-artic & Articulated & B-doubles & Length $^{19}$ & Route MRS $^{20}$ \\
\hline ACDB & 60 & 50 & 4 & 2 & 2 & 2 & 110 & 10 \\
AEFB & 0 & 0 & 0 & 0 & 0 & 0 & 151 & 10 \\
CDB & 10 & 5 & 1 & 2 & 2 & 0 & 78 & 10 \\
CAEFB & 0 & 0 & 0 & 0 & 0 & 0 & 183 & 10 \\
DB & 15 & 12 & 2 & 0 & 1 & 0 & 38 & 10 \\
ACD & 15 & 10 & 2 & 1 & 1 & 1 & 72 & 10 \\
CD & 20 & 14 & 1 & 2 & 2 & 1 & 40 & 10 \\
AC & 15 & 8 & 2 & 2 & 1 & 2 & 32 & 10 \\
ACF & 10 & 9 & 1 & 0 & 0 & 0 & 94 & 10 \\
AEF & 4 & 0 & 0 & 0 & 2 & 2 & 126 & 9 \\
CF & 30 & 22 & 4 & 4 & 0 & 0 & 62 & 10 \\
CDBF & 5 & 0 & 0 & 0 & 3 & 2 & 103 & 10 \\
AE & 80 & 65 & 7 & 4 & 4 & 0 & 92 & 8 \\
EFB & 120 & 108 & 10 & 2 & 0 & 0 & 59 & 12 \\
EF & 15 & 10 & 3 & 1 & 1 & 0 & 34 & 12 \\
FB & 10 & 8 & 2 & 0 & 0 & 0 & 25 & 12 \\
CFE & 25 & 18 & 3 & 4 & 0 & 0 & 96 & 11 \\
CAE & 3 & 0 & 0 & 0 & 1 & 2 & 124 & 9 \\
DBFE & 20 & 12 & 6 & 2 & 0 & 0 & 97 & 11 \\
DBF & 16 & 12 & 2 & 1 & 1 & 0 & 63 & 11 \\
Total & 473 & 363 & 50 & 27 & 21 & 12 & &
\end{tabular}

Table B3 Project data.

\begin{tabular}{lll}
\hline Project data & Base case & Project case \\
\hline Safe operating speed & $100 \mathrm{~km} / \mathrm{h}$ & $100 \mathrm{~km} / \mathrm{h}$ \\
Roughness & $100 \mathrm{NRM}$ & $100 \mathrm{NRM}$ \\
Curvature & Straight & Straight \\
Gradient & Flat & Flat \\
Discount rate & $4 \%$ & $4 \%$ \\
Capital cost per bridge & - & $\$ 1,500,000$ \\
Number of proposed bridges & 0 & 2 \\
Bridge standard & Q2 & Q50 \\
AATOC (annual average time of closure) & 108 & 0 \\
ADC (average duration of closure) & 170 & 0 \\
\hline
\end{tabular}

Table B4 Flood data.

\begin{tabular}{lll}
\hline General flood data & Base/project case \\
\hline Minor flood costs (anticipated) & $\$ 10,000$ & \\
Minor flood costs (unanticipated) & $\$ 20,000$ & \\
Moderate flood costs (anticipated) & $\$ 100,000$ & \\
Moderate flood costs (unanticipated) & $\$ 120,000$ & \\
Major flood costs (anticipated) & $\$ 5,000,000$ & Heavy vehicles \\
Major flood costs (unanticipated) & $\$ 6,000,000$ & 180 \\
\hline Average duration of closure & Light vehicles & 270 \\
\hline Minor & 120 & 180 \\
Moderate & 180 & \\
\hline
\end{tabular}

\footnotetext{
${ }^{19}$ Route length is the sum of section lengths comprised in the route.

${ }^{20}$ Route MRS is the weighted average of MRS of the sections comprised in the route.
} 
(Table B4 continued)

\begin{tabular}{ll}
\hline General flood data & Base/project case \\
\hline Major & 360 \\
ARI (average recurrence interval) & \\
Minor (anticipated) & 2 years \\
Minor (unanticipated) & 10 years \\
Moderate (anticipated) & 20 years \\
Moderate (unanticipated) & 20 years \\
Major (anticipated) & 40 years \\
Major (unanticipated) & 40 years \\
Maximum willingness to pay per km (anticipated flood) & $\$ 3 / \mathrm{km}$ \\
Maximum willingness to pay per km (unanticipated flood) & $\$ 4 / \mathrm{km}$ \\
Life of new bridge & 100 years \\
\hline Exogenous road user behavior applied to CBA6 & \\
\hline Waiting & $5 \%$ \\
Diverting & $90 \%$ \\
Not travelling & $5 \%$ \\
\hline
\end{tabular}

